\title{
斯大林和米邱林的農業生物䁷
}

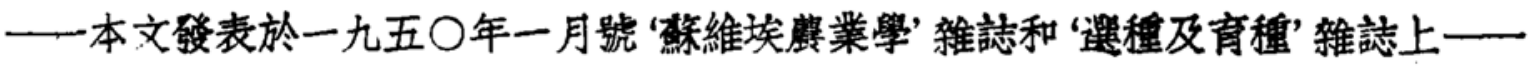

\section{李森科著 周邦立譯}

- 列窝——斯大林的社會主義農業發展的理諭 和斯大林的遖接領導, 在一儿二儿年中保證了我 國的震民階級的勞動鉒衆生活的最大轉變。蘇維 埃農民階級便走上了斯大林所指示的唯一正確的 道路上, 到圈結在集體農場中的社會主䣡的道路 上去。

由於斯大林同志的英明的領導, 在我國境內

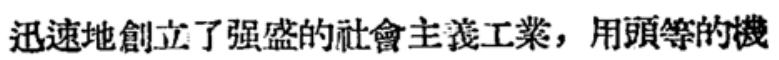
器和㖘業工具來配備了集體農場和國營農場。我 國的農紫已成第世界上最大的機悈化的農業, 蘇 聯的機器設偖年復一年地燴加着和盆瑧完善。

祇有在集體農場中, 農民們才能獲得真正的

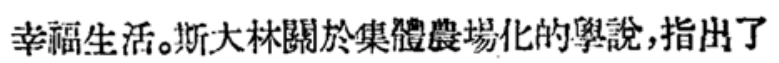

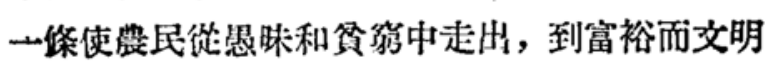
的創造站會主绕的生活大道上去的唯一正確的出 路。

集體農場和國營農場, 是科學加上了生活的 無限廣大的田地, 是利用科學作提高㖘業植物的

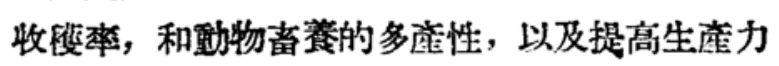
的田地。

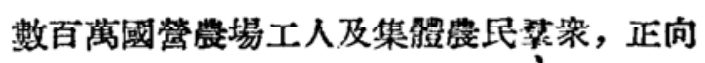
着科褱的知識, 向着創造力而仲展着。在腦力勞動 和能力勞動中間的界線正在日造消隇中。

䍿一切, 使我們非常感荷列密——斯大林的

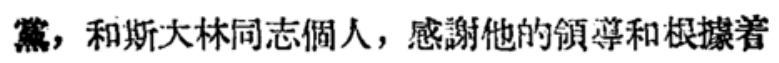
崇高的科學預見而提壮的英朋的指示以及他對勞 動者們的利谷方面的不斷關梳。

斯大林同志把强有力的馬克思祭渷的武器,

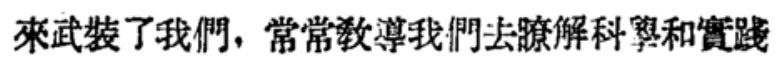
互相結合的必泪性。

斯:大林同志在他的著作“諭:棓證法唯物論 和 歷史的唯物論”一書中弿:

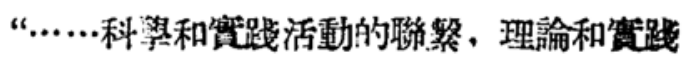

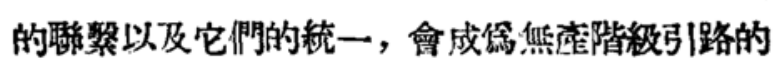

明星(北極星)。”

在第一次蘇聯斯造哈諾夫工作者會議上, 斯 大林同志的演講中說:

“科學的原理,總是用望践和用試驗來考驗

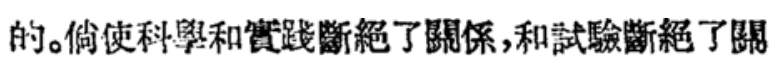
你、那末它還能算做科學嗎?倘使科學就是像我們 有些保守主義的同志們所形容的那一種東西, 那 末它對人類恐怕早已汥有什麼作用了。科率设所 以叫做科學, 就是因箼它不被認偶像, 不怕舉手推 翻陳舊的占董並䝷成㟬践和試驗。”

偉大的社會主接十月革命, 解放了人類的勞 動和理性, 發現了歷史上空前未有的科學發展的 可能性。如所週知, 在沙皇時代的宫庭的生物科學 中, 浔有一個人能知道天才的生物學家米邱林, 汥

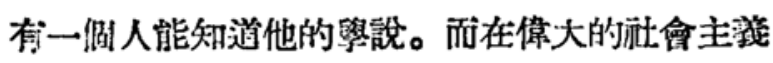
十月革命以後. 由於列案和斯大林對於有利於勞 動者們的科學墢鼠的天天關心, 米邱林的事泰,因 此獲得了大家的注悓。

米邱林的前進的唯物諭的生物學說, 是和沙 皇:我四所統治的唯心論的生物學—秒斯曼主 嫁、新達爾文主菻——根本相反的, 因此, 米邱林 的科學著作，在沙皇俄國時代便完全被人們所忽 視而不能使大家認識。如果汥有一九一七年的-1 月到臨, 米邱林恐怕永遠不能把他的進步性的生 物舉公諸於世了。

偉大的列察發現了米邱林。偉大的斯大林把 米邱林的唯物諭的生物學, 引䢘到一焂廣大的創 造性的道路上去。由於列玨和斯大林的支援。第了

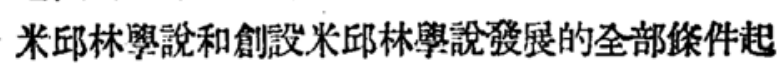
見.進步的生物學家們,將永遠感謝㯰二位偉大的 㴭導者: 列蔡和斯大林。

列賩和斯大林關心着人民的幸福, 就在僚大 的社會主荻十月革命以後, 立刻建立了對我國全 部科學部門缯展上的一切必需條件。 
米邱林的生物學說, 由於布爾什維克黨和斯 大林同志的距心和重視, 獲得了空前有利於它的 萿長的物質上與精神上的一切條件。數百萬聮維 埃费民階級。農業舉家和科學工作者們已經認識 了米邱林的工作和他的學說。

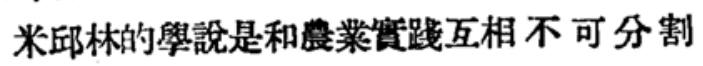
的。它是一程员正前進的生物科學, 不承認偶像、 不承認停慗不進的一種生物科學。它是在哣富的 農業望踐的試驗結果中所產生的, 並且是首先在 無數優良的獎果 一一 果樹植物新品種的栽培方

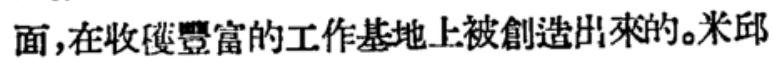
林揭發了一般生物學上的規律性: 在植物的生長 和生活時期中,外界環境條件能對它們起作用, 植 物和動物住機軆所獲得的新品性和新特徵可以遭 傅下去。

米邱林把他的工作來證明了植物界的本性是 可以控制的, 可以有定向地把它改禁到有利於人 類的農業惯践中去的。

農莱的䔈践因此獲得了强有力的方法; 用通 過農業技術和動物畜食技街來創造對植物及動物 生長與生活上的適當悠件的方法, 便可以改良動 物和植物形態的本性。

米邱林的學馀, 把達爾文主㢳提升到一個新 的階段, 把那種只是解釋有機體世界的起源的科 學, 㺲轉而成瓷可以有定向地改變和改造有機體 世界的科學。

我們的邧會主㹻農業, 不知道什麼叫做危機 和停㴆的脤業, 必然地需求着前進的唯物諭的生 物舉, 把它們作第農業科學的理諭基礎。

陳舊的、反動性的唯心諭的生物學一峨斯 曼主㼁(新達爾文主義)一一不適合於現察的生物 學上的規律性，並且也和現實的生物學互相對敵。 因此,它不能成纱農業科䀢的畺正的理諭基礎。

列密和斯大林, 早在偉大的社會主鸴十月革 命後的起初幾年中, 天才地預見了唯物諭的生物 學的浐展的必然性。㯰可以用下面的事顀來澄朋。

在一九二二年二月十八日，第了要報告列察 關於米邱林的工作和實驗情形，人民委員會便拍 墢給達姆波夫省執委會一通訊問的電報, 襄面指 出說 :

“在新的裁培植物的獲得方面的賽驗, 具有巨 大的國家意液……”

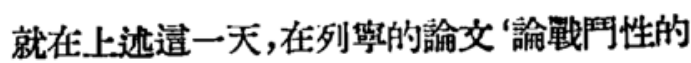
唯物諭的意练，一文中，他指出了：

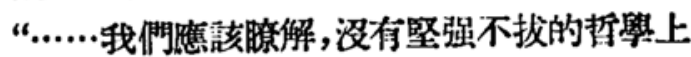
的改革,任何的自然科學, 任何的唯物諭, 便不能 持久铔對抗資厘階級思想的進攻和對抗资隺階級

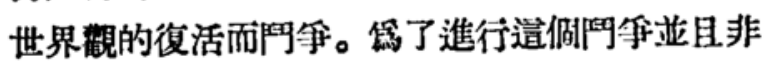
常順利地把它進行到底起見, 自然科學家便應辞 成篇一位讙證法的唯物諭者。”

- 斯大林也和列蜜一樣地重涀着那些和資育階

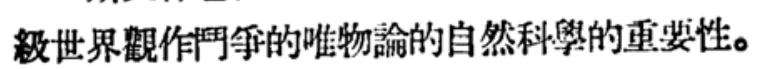
他以天才的遠見, 支报了米邱林和他在管践性的 果樹園藝上的工作。斯大林同志看到了並知道了 米邱林對生物學和農業生物學方面的見解是具有 科學上的和賽践上的重要性的。到現在,蔡聯的全 體生物學家們和其他各國的進步的生物學家們都 清楚地瞭解了米邱林對生物學所作的見解, 就是 唯一正碓的見解。

偉大的斯大林不僅琭救了米邱林㠘說, 使他 盼㟝了反動者們要清除它出科學之外的企图, 亚 且也助長了學者和筫践家的米邱林主涹者們的幹 部的增加。

在蘇聯境內,對於唯物諭的米邱林學說, 在戰 勝反動的唯心諭的秘斯曼—摩根主找方面, 斯 大林的主运思想曾起了和正起着决定性的作用。

B - P - 威廉士的學說, 正隻地反胑了土壤 發展和土壤基本特性一一肥沃性的規律性。在望 践中, 在集體農場和國營農場中, 他的學說便宣告 了那些過去列察早已反對過仢, 反動學者们所狂 吹的所謂上铱的“肥沃性減退的定律”的破产。

米邱林的學說和威庭士的學設正是唯一的唯 物論的生物科學的二支巽途同的學铅, 都不承 認陳蒣的唯心諭的生物學, 並且已經在社會主玟

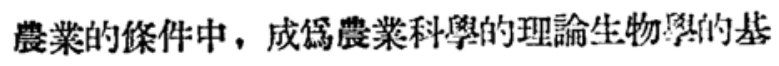
礎, 在唯一的米邱林的農業生物科學中融合在一 起。

因此, 米邱林的㖘恶生物科學, 在社會主㴽農 業中、在集體農場和國營農埸中, 造成了歷史上空 前未有的對於它的應用和弡展方面的攸件。米邱 林的理論和集體農場一一國營農場的缤践的互相 結合, 成第農業生物學的一個主要的生活力量, 農 菜生物學內部力量的源泉。在解答它所提比的最 深奥的理諭上的問題中, 總是遖接或間接地. 通過 
了各種重大的實践上的問題的答案而完成的。農 業生物學的旨趣也就是實践的旨趣。因此在研究 深奥的科學的農菜生物學的問題中, 在通過農掌

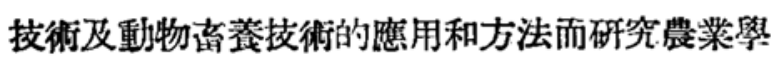
所反脥的問題中, 是包括着農業科學工作者、農業

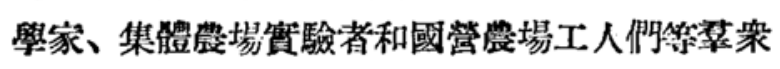
的互助合作。

斯大林的發展葆聯農業的計劃已順利地被集 體農場和國營農場完成了。同時這一計劃也是對 農業生物學方面的一個課題。生物學的和農業學 的科學慗助了敗践, 就是幫助了集體農場和國營 農場在它們的完成國家計劃上的工作中的實践; 同時也發展了和改進了這二種科學的自己本身。

我國社會主㼁滞業的一切有堵魚已的進步, 也助長了我們的農桬生物學的順利墢展。

斯大林同志的著作, 對於米邱林的理論生物

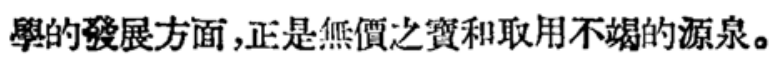

斯大林的經典著作讋登法唯物論和歷史唯物 論 一書, 對於我們全體的農業生物學的工作者 椚, 正是生物學現象的正磼概念的和永垂不朽的 一般的理論基礎。對於我們, 只有站在斯大林同志 所發展的讋登澄法唯物諭和歷史唯物論的立場上, 才能忿谷斯露出米邱林的生物學說的深度和真實 性。

斯大林同志提出了對暴露出生物界發展的規 律性方面的强有力的理論上的武器。剩藉着造一 程武器, 蘇聯的生物學家和農業學家們, 能更遠地 和更深地發展米邱林的學說並藉此對集體農場及 國營農場作更大而更有效的埣助。

除了列察和斯大林以外, 世界上不椧過去和 現在,是沒有人能這榡本關心科學,關心科學的椇 實性和理諭的正確性了。除了列穿和斯大林以外, 世界上過去就汥有人能對我們鿶聯和全世界勞動 者們的生活和對科學提供出邆栐多的封助了。

理諭生物學的發展完全說明了科學工作者們 已精通了傅播和㮣用讋證法唯物諭來解釋古今許 多生物學中的事暂及現象。䄐植精通是和生物學 中事筫和現象的解釋以及研究方法的蕒賽性和研 究態度的燕筫性互相有關的。

生物颈正是唯物諭和唯心論中間的醖戰未休 的角門場。在我們的時代中，還得更属害地暴露出
唯物論和唯心諭在哲學中的矛盾。在生物學中也 同樣猛烈地仵現了唯物論和唯心論中間的矛盾。

只有列察和斯大林的著作所提升到空前高度 的唯物論的學說; 已提供了和正提供給我們造些

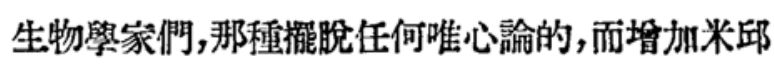
林的唯物論生物學的可能性, 並嶑此理解到生物 界的發展, 正是物質蓮動的一種特㱛形式, 用它們 來理解生物界和它的規律性。

活生物總是有更多生活力或更少生活力, 正 如每:天的觀察所見的生活力總是有多或有少, 並 首這程生活力, 因有機钽和身體的倜别部分的逐

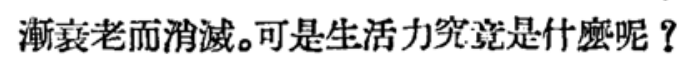

唯心論者一生物學家們都認罵生活力是匴

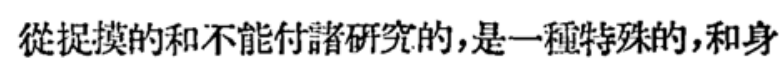
體遠離的 “生活的力量”。唯物論者一生物學家 們正碓地排斥了並反對了這程概念, 這種非科學 的神秘主義的概念。可是, 唯物諭若不含有馬克思 一一列鼻的讋證法, 便不能解釋生活力是什窟東 西。

米邱林的學說，應用着斯大林同志所發展的 馬克思一列㹸的讋證法, 而据示了生活力的源 泉, 有機體的生活衙動的源泉。

列察和斯大林畣敉运我佃涗：连動着的發展 力量,便是對象和現象的內在的矛盾。

正和形而上學相反，拜證法是從自然界的對 象、自然界的現象含有着內在的矛盾的見解而作 出發的。斯大林同志在他的著作“䩧證法唯物諭和 歷史唯物諭'一書中就指出了邆一點。斯大林同志 引用列寗的话:

“讋證法按其本莪來涗, 便是研究對象自身內 部的矛盾的” (見列蜜著“哲學筆記第二六三面)。

“發展就是互相對立方面的“班乎””(列察全集 第十三管第三○一项)。

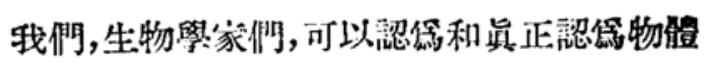
的生活衙動, 它的生活力的程度是受到有機體的

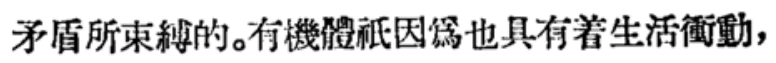
才使它特有湴內部的矛盾。

在䄐程對有機艘的生活力的現象的見解下， 清楚地說明了肧胎過程的生物學上的特色。还胎 創造了生活力、生活衝動。在某一方式下, 不同的 性細胞(雌性和雄性)的結合在一倜細胞中, 用二 種性細胞的核結合在一個細胞核中的方法, 造成 


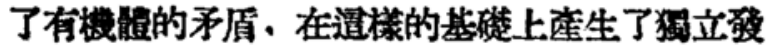
展、立運動和生命的過程一同化作用和異化 作用以及新陳代謝作用。

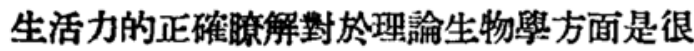
重要的. 同時對於费菜作物的裁培上的和動物音 以上的管践也很重要。在筧践性的育種中，用適常 的中間品種和內部品種的雜交, 會獲得一種更有 生活力的種子, 更加堅强的植物。在動物的音養 中, 若應用遠摬間的雜交, 也可以獲得相同的結 果。

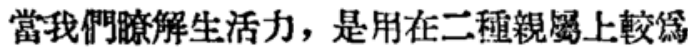
生䟽的性細胞結合成一骿的絬果中的受精方法而 創造出來的時㑨, 便可以在植物㭖培棠的植物新 品整的作成中,施行花粉傅授的雜交工作。同樽地 也可以在畜牧丵的動物新種的創造中, 良好地進 行遠親繁殖的工作。造種工作不僅能保伱父母本

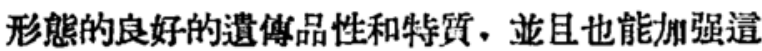
些品性和特筫。

编了在遠摬繁殖時不減低生命力起胃，用作

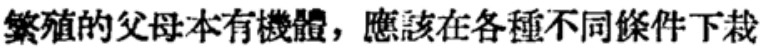
培的來。

唯心論者所認第不可捉摸的“生活力量”,對於 米邱林的生物學却咸㟓一種可認諳的, 也是可以 控制的東西。對於造件事，我們不得不感謝在列臱

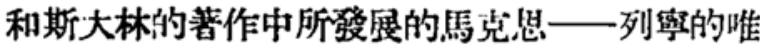
物論的學說。斯大林同志會教薄我們說：

“馬克思主涹的哲學唯物論,却和它(唯心論) 相反，認篇：世界及其规律性是完全可以認識的; 我們對於自然界規律的那些已經由經驗和譄践所

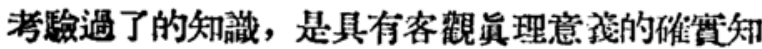

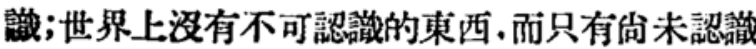
的東西,並且這些少未認識的東西,是由於科學和 资践的力量而揭簬和認識的。”

斯大林用他的著作，忠告和指示教導了和呚

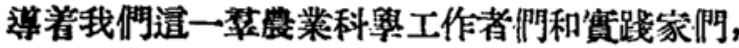
去叒加深切地瞭解和更多多地鑑别及發展 進步 的生物 學家 一一季米里亞席夫, 米邱林和威廉 士一一的㯋說。

在斯大林所㮣用的棓證法唯物渝見解的絕俳

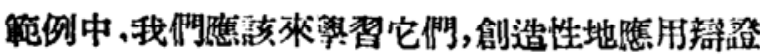
法唯物論去作生物學現象的研究和科學的說明, 耤此可以控制它們而合於筧践家的需求。
只有逜一绦路會引導我們去順利解让那些梗 阻在生物科舉大道上的困難阳題。

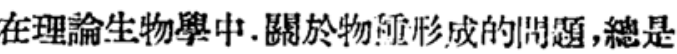
成第中心的論争之點, 暹爾文的不朽苦作,科學地 證明了: 有機體圮界是不断地在變化着,發展着; 登明了: 有機體世界具有它的愁史,它的過去、現 在和將來。達爾文的最偉大的功縝就在於登朋了 生物界是在自然法则的基群上發留着的。

但是達爾文的進化諭, 却衿第祇有量的戀化 一祇是發生在坦加或減少方面的變化：蓝且忽 略了, 也可以說是不知道從那一秚㖵的状况過渡 到、轉變到另一種質的爿况的規律性和必然性。闹

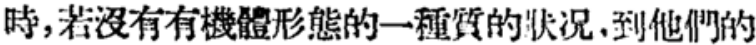

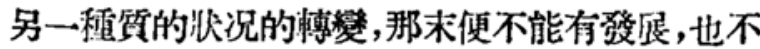

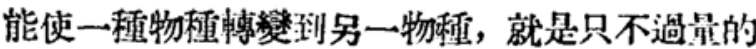
坦加或減少吧了, 只不過是一乘普通的所謂加減。

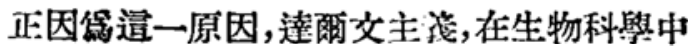

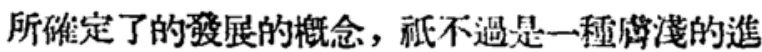

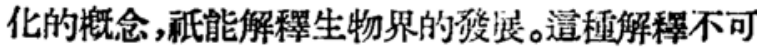
能成第一種员正的有效的理䃋, 不可能成铅一程 貨践上的改革和有計劃地改變生物本性的理諭基 磷。

只有在斯大林同志的等作所發展的馬点思主

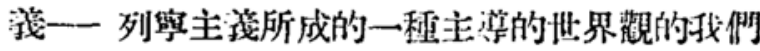

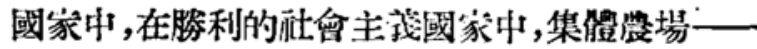

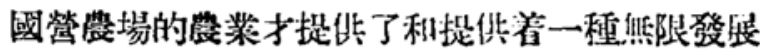

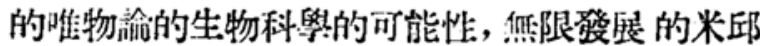

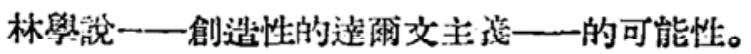

“......和形而上學相反, ”折大林同志教染我

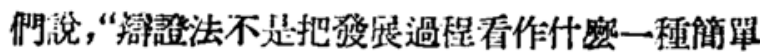
増灯的過程,看作量變不會引起许變的過程,而是 看作由米察學的和微小的量進向敇路的可見的量 的變化,進向根本的變化,就是進到筫變的發展過 程。在這湖過程中,質變亚不是逐漸地發生，而是 迅速地和笑然地發生，就是從一䡌狀態突變成另 一雷护態。它蓝不是偶然發生的.而是從听多微小

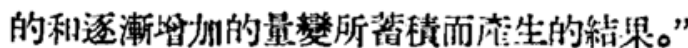

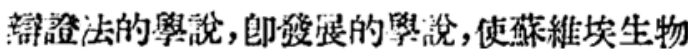
學家可能去發現一焂將一㻎植物酒類改變成别一 種類的道路。

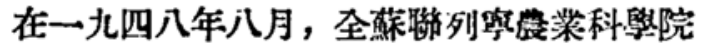


寒行會議時所作的報告諭生物科學的現贸'中, 作 者會简略地指所過：一種含有二十八㟠染色體的

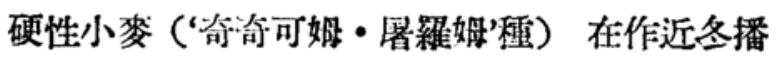

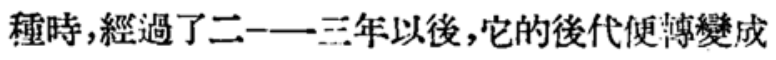
另一程小麥——含有四十二個染色鳢的惨性小麥 （“奇奇可姆・驸隬格里”種）。同時又靧示出, 在有

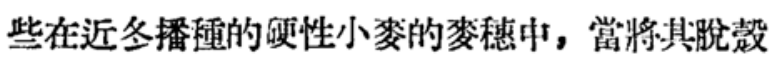

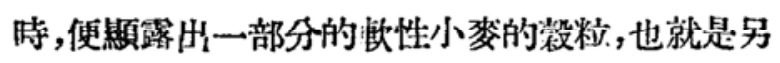
一種植物學上的品種。

從硬性小麥的苏子中播生出的軟性小㽜植物

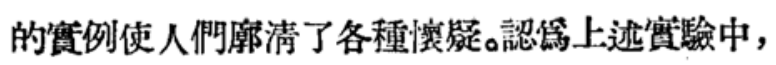
可能將硬性小麥種一作偶然的、微小的、機悈烒的

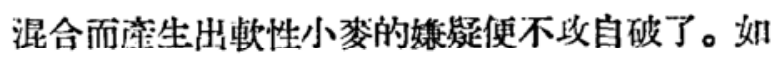

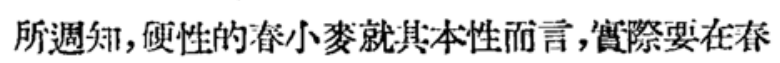
天播想的。而對便性的春小麥所不㕷慣的秋一 冬的籍候條件的影響, 發生了一種微小的和未學 察的量的變化在硬性小麥的植物細胞中的蓄積。 濖種硬性小麥的植物, 不渝按其外表或按其細胞 核中的染色體的数量, 都是和普通的硬性小梦一

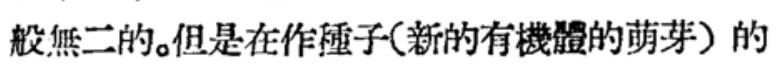
栽培晴, 經過了二一三年的近冬播種, 便在這程 小麥的麥穗中, 有一部分程子已經獲得了不是母 本的形式, 而是另外一衄激的植物學上的形式。在 上述情形中, 因此在硬性小麥的䄲穗中發生了一 部分饮性小华的乘了壮来了。

根碾了上面選些實䮑, 有很多的科學工作者 和農薂學家們, 在一儿四儿年中, 以絕對的確資性 來澄明了: 在山管和山地澡域中, 在越冬時有不利 㷛件的地區中和特别是在對生長上,具有不利條件 的區域中, 冬小装便可以轉變成虽裸麥。

古時候的人們, 已經知道了關於小麥能轉化

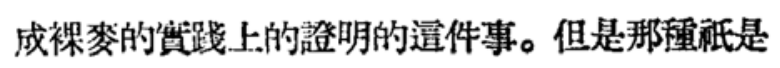
根據着潵淺的進化諭的理論科學一簡單地可說 它是有一偪䢹爁在阻擋着的科學——却否定了一 程植物學上的程類突變成另一 程類的可能性。在

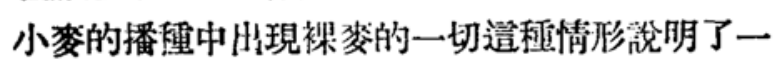
種砈是它的機珹性的阻塞的結果。

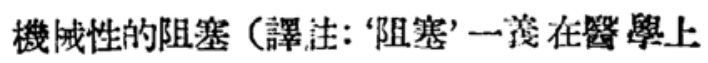

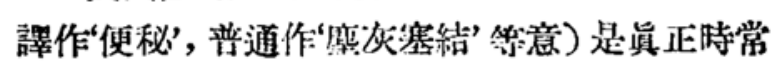
發生的事。因此也用不到多涗, 郎以遭件事而言, 就證望了用適賞的條件把小麥轉變成裸麥的可能 性。
斯大林關於逐潮的、未蓜察的和微小的数量 變化會進向迅速的和根本的性賈的轉變的凳說,

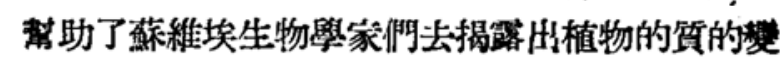
化的現仔事實，一整物程轉變到另一物锤的事宽。

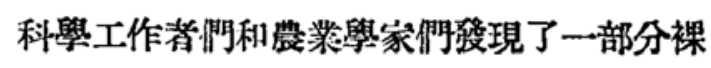
麥的福子, 這是在外形上和普通小麥一般無二的 那留小麥的麥稆中結生着的员正是裸麥的種子。

這些事實正直捷地說明了：在某種生活條件 下,在小麥植物中正举生着微小的, 未㦛察的和逐 漸的量的變化, 這種變化發生了一部分植物細胞 作迅速的、突然的和明智的轉紮, 在上迅情形中, 小缹植物的卿形細胞,變成了另外一種了。代替了 小麥的細胞而產生了褋㽜的細胞。

這些米邱林農業生物學上的事望,現在已經 積糸了很多。扼要地說, 在朋瞭外然的環境佟件” 明瞭它的影響會迫使一種植物品程, 轉變成另一 䊗更適應於核地的外界環境悠件的品種時, 這些 事触將源源不絕地年年兴生着。

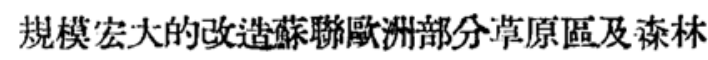

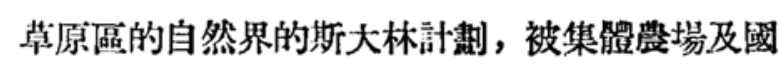
營農場所順利地執行着, 它在科學工作者及筫践 家們之前渴示了一種新的哭限廣大的創造性底力 量和知識相加的活重力的田地。

集體農場和國營農場, 在數世紀來汥有過天 然森林的地區中裁培了數百䓪公頃的森林掩蔽带 和森林褧。

集體農民們，國營農埸工人們，農㴽祭家們及 科學工作者們, 在列察——斯大林的黨和蘇聯政 府的領尊下,在我們的偉大 的領袖良導師斯大林 同志的領等下, 如期地靾行着國家的椂林裁植的 任務, 蓝創設了有利於森林的生長的條件。

斯大林同志,造是人民的智慧的實質化,造是 我們的偉大的蘇維埃聯邦的勞動者們的真理, 迢 是企世界勞動者們的垶福。

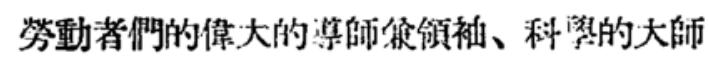
斯大林同志萬祴！

(完)

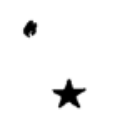

